\title{
Pre-Conception Interventions for Subfertile Couples Undergoing Assisted Reproductive Technology Treatment: Modeling Analysis
}

Régine Steegers-Theunissen ${ }^{1}, \mathrm{MD}, \mathrm{PhD}$; Annemieke Hoek ${ }^{2}, \mathrm{MD}, \mathrm{PhD} ;$ Henk Groen ${ }^{3}, \mathrm{MD}, \mathrm{PhD}$; Annelies Bos ${ }^{4}, \mathrm{MD}$, $\mathrm{PhD}$; Grada van den Dool ${ }^{5}$, MD; Marieke Schoonenberg ${ }^{6}, \mathrm{MD}$; Jesper Smeenk ${ }^{7}, \mathrm{MD}, \mathrm{PhD}$; Eva Creutzberg ${ }^{8}, \mathrm{PhD}$; Loes Vecht ${ }^{9}$, MD; Luc Starmans ${ }^{9}$, PhD; Joop Laven ${ }^{1}$, MD, PhD

${ }_{1}^{1}$ Department of Obstetrics and Gynaecology, Erasmus MC, University Medical Center, Rotterdam, Netherlands

${ }^{2}$ Department of Obstetrics and Gynaecology, University Medical Center Groningen, University of Groningen, Groningen, Netherlands

${ }^{3}$ Department of Epidemiology, University Medical Center Groningen, University of Groningen, Groningen, Netherlands

${ }^{4}$ Department of Reproductive Medicine and Gynecology, University Medical Centre Utrecht, Utrecht, Netherlands

${ }^{5}$ Department of Obstetrics and Gynaecology, Albert Schweitzer Hospital Zwijndrecht, Zwijndrecht, Netherlands

${ }^{6} \mathrm{Nij}$ Geertgen Centre for fertility Elsendorp, Elsendorp, Netherlands

${ }^{7}$ Department of Obstetrics and Gynaecology, Elisabeth-TweeSteden Hospital Tilburg, Tilburg, Netherlands

${ }^{8}$ Department of Gynaecology, Ferring BV Hoofddorp, Amsterdam, Netherlands

${ }^{9}$ KPMG, Amsterdam, Netherlands

\section{Corresponding Author:}

Régine Steegers-Theunissen, MD, PhD

Department of Obstetrics and Gynaecology

Erasmus MC

University Medical Center

Office EE-2271a, Dr.Molewaterplein 40, 3015 GD

Rotterdam

Netherlands

Phone: 31107038255

Email: r.steegers@erasmusmc.nl

\section{Abstract}

Background: Approximately 1 in 7 couples experience subfertility, many of whom have lifestyles that negatively affect fertility, such as poor nutrition, low physical activity, obesity, smoking, or alcohol consumption. Reducing lifestyle risk factors prior to pregnancy or assisted reproductive technology treatment contributes to the improvement of reproductive health, but cost-implications are unknown.

Objective: The goal of this study was to evaluate reproductive, maternal pregnancy, and birth outcomes, as well as the costs of pre-conception lifestyle intervention programs in subfertile couples and obese women undergoing assisted reproductive technology.

Methods: Using a hypothetical model based on quantitative parameters from published literature and expert opinion, we evaluated the following lifestyle intervention programs: (1) Smarter Pregnancy, an online tool; (2) LIFEstyle, which provides outpatient support for obese women; (3) concurrent use of both Smarter Pregnancy and LIFEstyle for obese women; (4) smoking cessation in men; and (5) a mindfulness mental health support program using group therapy sessions. The model population was based on data from the Netherlands.

Results: All model-based analyses of the lifestyle interventions showed a reduction in the number of in vitro fertilization, intracytoplasmic sperm injection, or intrauterine insemination treatments required to achieve pregnancy and successful birth for couples in the Netherlands. Smarter Pregnancy was modeled to have the largest increase in spontaneous pregnancy rate (13.0\%) and the largest absolute reduction in potential assisted reproductive technology treatments. Among obese subfertile women, LIFEstyle was modeled to show a reduction in the occurrence of gestational diabetes, maternal hypertensive pregnancy complications, and preterm births by $4.4 \%, 3.8 \%$, and $3.0 \%$, respectively, per couple. Modeled cost savings per couple per year were $€ 41$ (US \$48.66), €360 (US \$427.23), €513 (US \$608.80), €586 (US \$695.43), and €1163 (US \$1380.18) for smoking cessation, mindfulness, Smarter Pregnancy, combined Smarter Pregnancy AND LIFEstyle, and LIFEstyle interventions, respectively. 
Conclusions: Although we modeled the potential impact on reproductive outcomes and costs of fertility treatment rather than collecting real-world data, our model suggests that of the lifestyle interventions for encouraging healthier behaviors, all are likely to be cost effective and appear to have positive effects on reproductive, maternal pregnancy, and birth outcomes. Further real-world data are required to determine the cost-effectiveness of pre-conception lifestyle interventions, including mobile apps and web-based tools that help improve lifestyle, and their effects on reproductive health. We believe that further implementation of the lifestyle app Smarter Pregnancy designed for subfertile couples seeking assistance to become pregnant is likely to be cost-effective and would allow reproductive health outcomes to be collected.

(JMIR Mhealth Uhealth 2020;8(11):e19570) doi: $\underline{10.2196 / 19570}$

\section{KEYWORDS}

fertility, periconception, pregnancy chance, Smarter Pregnancy, cost-effectiveness, nutrition, obesity, IVF treatment; mobile and web-based lifestyle apps

\section{Introduction}

Many couples who undergo fertility treatment have multiple lifestyle risk factors that reduce their chances of becoming pregnant [1]. Female lifestyle risk factors such as smoking, alcohol use, and poor diet are inversely associated with fecundity and time to pregnancy, and the effects of these factors increase with increasing BMI [2]. Chronic stress or high anxiety levels reduce fecundability, and high depression scores are also associated with subfertility [3]. Furthermore, evidence is accumulating that poor nutrition, stress, drug use, infection, or exposure to environmental chemicals during prenatal development has a life-long impact on offspring health as shown by the Developmental Origins of Health and Disease paradigm [4]. Obese pregnant women are more likely to have gestational diabetes, hypertensive complications, premature delivery, higher risk of cesarean delivery, and fetal death [5]. Obese men are more likely than men of normal weight to have lower sperm quality [6].

Despite the evidence available, weight-loss interventions in overweight or obese couples prior to fertility treatment remain controversial, as there is limited evidence that these interventions increase the chance of a live birth or reduce pregnancy complications $[7,8]$. Two well-conducted randomized controlled trials $[9,10]$, however, show that spontaneous conceptions significantly increased with pre-conception weight-loss lifestyle interventions in obese subfertile women and led to lower number of fertility treatments, though neither trial showed an increase in assisted reproductive technology treatment-dependent pregnancies.

Health care budgets are increasingly under pressure due to noncommunicable diseases associated with an aging population, scarcity in the workforce, and rising costs of novel medical technologies. It is, therefore, key that lifestyle interventions aimed at subfertile couples improve reproductive outcomes and in a cost-effective manner.
The aim of this evaluation was to estimate and model the impact of pre-conception lifestyle interventions on the likelihood of the occurrence of pregnancy, and maternal pregnancy and birth outcomes after fertility treatment in subfertile couples and in subfertile obese women, as well as to assess whether these lifestyle interventions are cost-effective.

\section{Methods}

\section{Overview}

We created a hypothetical model to estimate the effectiveness of pre-conception lifestyle interventions on reproductive, pregnancy, and birth outcomes and potential cost savings in subfertile couples, including a subgroup of subfertile obese women, undergoing in vitro fertilization (IVF), intracytoplasmic sperm injection (ICSI), or intrauterine insemination (IUI) treatment.

\section{Lifestyle Factors Relevant to Fertility Care}

Modifiable factors most relevant to fertility treatment, reproductive health, and pregnancy complications with compelling quantifiable clinical published evidence were women's BMI (a marker of health and lifestyle), diet (nutrition intake), physical activity, smoking cessation, and stress [2,9,11-23].

\section{Pre-conception Lifestyle Interventions}

Five lifestyle interventions matching the selected lifestyle factors were selected by the fertility experts for inclusion in the cost-effectiveness model (Table 1). These programs included support for changing lifestyle factors deemed most relevant to pre-conception care that were outlined above. The programs used in our model were Smarter Pregnancy [12,20], and LIFEstyle $[9,11]$. We also modeled smoking cessation in men by using analysis of IVF and ICSI outcomes in men who smoke and men who do not smoke [24], and mindfulness-based mental health support for couples undergoing IVF [16]. 
Table 1. Lifestyle interventions selected for cost-effectiveness modeling.

\begin{tabular}{|c|c|c|}
\hline Name & Model target population & Description \\
\hline $\begin{array}{l}\text { Smarter Pregnancy interven- } \\
\text { tion } \\
{[12,20]}\end{array}$ & $\begin{array}{l}\text { Women aged } 25-44 \text { years trying to con- } \\
\text { ceive, comprising subfertile couples } \\
\text { seeking medical assistance to conceive } \\
\left(\mathrm{IVF}^{\mathrm{a}} / \mathrm{ICSI}^{\mathrm{b}}\right) \text { and fertile couples }\end{array}$ & $\begin{array}{l}\text { Provides } 26 \text { weeks of individual online coaching and information via smart- } \\
\text { phone tailored to improve nutrition and lifestyle during the pre-conception } \\
\text { and pregnancy period in order to improve the health of the reproductive } \\
\text { population and subsequent generations }\end{array}$ \\
\hline $\begin{array}{l}\text { LIFEstyle intervention } \\
{[9,11]}\end{array}$ & $\begin{array}{l}\text { Obese subfertile women with BMI } \\
>29 \mathrm{~kg} / \mathrm{m}^{2} \text { seeking fertility treatment }\end{array}$ & $\begin{array}{l}\text { Provides } 6 \text { outpatient visits (each } 30 \text { minutes long) and } 4 \text { telephone consulta- } \\
\text { tions ( } 15 \text { minutes) during a } 24 \text {-week period to provide motivation and support } \\
\text { for nutrition (energy restriction of approximately } 500 \mathrm{kCal} / \text { day) and exercise } \\
\text { strategies }(10,000 \text { steps per day, } 2-3 \text { moderate vigorous exercise sessions per } \\
\text { week for weight loss in obese women (BMI }>29 \mathrm{~kg} / \mathrm{m}^{2} \text { ) seeking fertility } \\
\text { treatment }\end{array}$ \\
\hline $\begin{array}{l}\text { Combined Smarter Pregnan- } \\
\text { cy and LIFEstyle interven- } \\
\text { tion }[9,11,12,20]\end{array}$ & $\begin{array}{l}\text { Combination of the } 2 \text { target audiences } \\
\text { mentioned above }\end{array}$ & $\begin{array}{l}\text { Providing both Smarter Pregnancy and LIFEstyle support for obese women } \\
\text { (the remaining couples were modeled to receive the Smarter Pregnancy inter- } \\
\text { vention only) }\end{array}$ \\
\hline Smoking cessation [24] & Subfertile men who smoke & $\begin{array}{l}\text { Comparison of IVF and ICSI outcomes in male smokers and non-smokers } \\
\text { from couples seeks reproductive assistance }\end{array}$ \\
\hline Mindfulness support [16] & $\begin{array}{l}\text { Subfertile women undergoing their first } \\
\text { IVF or ICSI cycle }\end{array}$ & $\begin{array}{l}\text { Comparison of IVF outcomes in couples either receiving or not receiving } \\
\text { group sessions to teach stress reduction through a mindfulness-based inter- } \\
\text { vention while undergoing IVF treatment }\end{array}$ \\
\hline
\end{tabular}

${ }^{\mathrm{a}}$ IVF: in vitro fertilization.

bICSI: intracytoplasmic sperm injection.

\section{Model Population and Treatment Policies}

The model population comprised couples living in the Netherlands seeking fertility treatment, representing a general subfertile population including a subgroup of obese women. The prevalence of subfertility in men and women living in the Netherlands aged $25-45$ years was $0.7 \%$ and $2.2 \%$, respectively, representing approximately 15,000 men and 46,000 women who are subfertile (Multimedia Appendix 1). Based on available published data $[25,26]$, we calculated that there were 5400 subfertile obese women, 3200 smoking men, and 13,700 women undergoing their first IVF or ICSI cycle. Based on clinical experience, we assumed approximately $24 \%$ of the couples living in the Netherlands seeking assisted reproductive technology treatment received IVF treatment (mean 1.5 cycles), $16 \%$ received ICSI (mean 1.5 cycles) in total per couple, and $60 \%$ received IUI (mean 3.0 cycles). We did not include couples seeking ovulation induction in our model.

\section{Modeling Clinical Outcomes}

For each pre-conception lifestyle intervention program, the published data were reviewed to determine input parameters for the model to estimate the intervention's impact on chance of a spontaneous ongoing pregnancy (a viable pregnancy at week 12), number of IVF, ICSI, and IUI treatments, as well as on pregnancy complications - gestational diabetes, gestational hypertensive complications, and preterm delivery-expressed per couple per year. For each lifestyle intervention, the model only included the fertility treatments and known complications from the lifestyle intervention according to high quality evidence.

\section{Modeling Potential Cost Savings}

The general structure of the cost-effectiveness model is depicted in Figure 1. The cost-effectiveness evaluation was performed from a health care perspective and included direct medical costs of the lifestyle intervention, fertility treatments, medication, and any resulting pregnancy. The model (business case) was designed to estimate the cost impact of the selected lifestyle interventions on fertility and obstetric care per subfertile couple, expressed as the difference in costs per patient or per couple and the overall cost difference per year in the Netherlands. 
Figure 1. General structure of the cost-effectiveness model for each lifestyle intervention. IUGR: intrauterine growth restriction; IUI: intrauterine insemination; IVF: in vitro fertilization; ICSI: intracytoplasmic sperm injection.

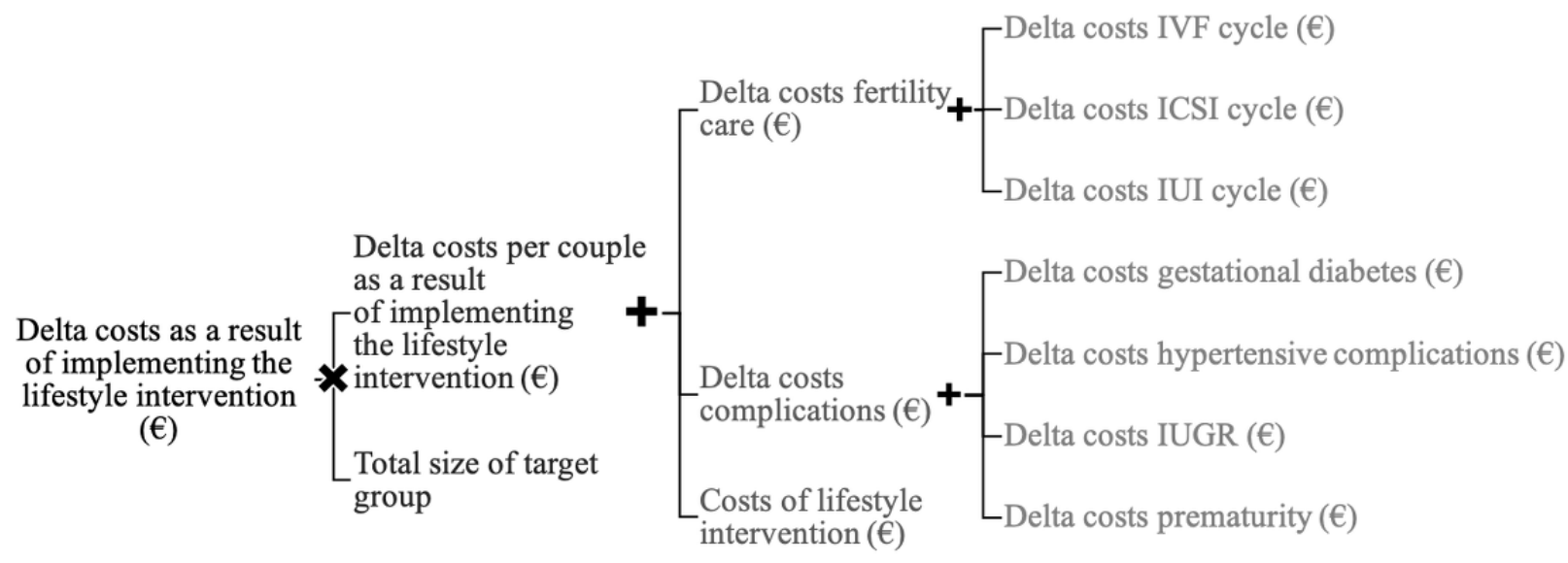

\section{Model Input Parameters}

The effects of the respective interventions on each of the selected lifestyle factors were modeled according to available published literature or expert opinion agreed by consensus. Costs for ovulation induction prior to IUI were not included as part of the cost-effectiveness model. Where published data existed, previously estimated costs of pregnancy complications, such as fetal growth restriction, gestational diabetes, gestational hypertensive complications (including preeclampsia), and premature birth, were used.

The general costs for assisted reproductive technology and pregnancy are presented in Multimedia Appendix 1. Costs, indexed to 2016 price levels, for pregnancy, birth and admission until 6 weeks postpartum in singleton and multiple pregnancies conceived after IVF were estimated.

Specific parameters related to each pre-conception lifestyle intervention are presented in Multimedia Appendix 2 including costs of the intervention, the estimated costs of pregnancy outcomes, chances of spontaneous pregnancy, intrauterine growth restriction, and gestational diabetes or hypertension. For each lifestyle intervention that was modeled, the estimated impact on fertility treatment or pregnancy outcomes were only included if there were data to support effects associated with that specific lifestyle intervention.

\section{Results}

\section{Modeled Impact of Lifestyle Interventions on Clinical Outcomes}

The modeled impact of lifestyle interventions on fertility outcomes, including the reductions in assisted reproduction and pregnancy complications, are presented in Tables 2 and 3. Each of the 5 modeled lifestyle interventions showed a reduction in the number of IVF and ICSI treatments per couple required to achieve a successful ongoing pregnancy. Smarter Pregnancy in the subfertile couples and LIFEstyle in subfertile obese women resulted in 10,800 (23.4\%) and 1100 (20.0\%) fewer IUI cycles, respectively, among the modeled population for the Netherlands than if no lifestyle intervention was used. Overall, Smarter Pregnancy was modeled to have both the largest increase in the number of spontaneous pregnancies $(6000$ additional spontaneous pregnancies among the modeled population, which is a $13 \%$ reduction in the number of couples who require assisted reproductive technology treatment) and the largest reduction in potential number of assisted reproductive technology treatments per couple $(4.7 \%$ for in vitro fertilization, $3.1 \%$ for intracytoplasmic sperm injection, and $23.4 \%$ for intrauterine insemination). Smarter Pregnancy was associated with a reduction of fetal growth restriction by $2.6 \%$, and LIFEstyle was associated with a reduction of gestational diabetes (4.4\%), gestational hypertensive complications (3.8\%), and preterm delivery $(3.0 \%)$. There were no published data regarding the effects of smoking cessation or mindfulness on the likelihood of achieving spontaneous pregnancies, or on fetal growth restriction, gestational diabetes, hypertensive, or premature birth pregnancy complication. 
Table 2. The effect of each lifestyle intervention on assisted reproductive technology clinical outcomes modeled for the Netherlands.

\begin{tabular}{|c|c|c|c|c|}
\hline \multirow[t]{2}{*}{ Intervention } & \multicolumn{4}{|c|}{ Modeled changes in clinical results (per year) } \\
\hline & Spontaneous pregnancies, $\mathrm{n}(\%)^{\mathrm{a}}$ & $\mathrm{IVF}^{\mathrm{b}}$ treatments, $\mathrm{n}(\%)$ & $\mathrm{ICSI}^{\mathrm{c}}$ treatments, $\mathrm{n}(\%)$ & $\mathrm{IUI}^{\mathrm{d}}$ treatments, $\mathrm{n}(\%)$ \\
\hline $\begin{array}{l}\text { Smarter Pregnancy } \\
\text { (SlimmerZwanger) }\end{array}$ & $+6000(13.0)$ & $-2200(-4.7)$ & $-1400(-3.1)$ & $-10,800(-23.4)$ \\
\hline LIFEstyle & $+500(9.9)$ & $-600(-11.3)$ & $-1000(-18.9)$ & $-1100(-20.0)$ \\
\hline Smarter Pregnancy + LIFEstyle ${ }^{\mathrm{e}}$ & $+6000(13.0)$ & $-2500(-5.5)$ & $-2300(-5.0)$ & $-10,800(-23.4)$ \\
\hline Smoking cessation (men only) & $-f$ & $-300(-0.8)$ & $-100(-0.4)$ & - \\
\hline Mental health/ mindfulness & - & $-1600(-11.8)$ & $-100(-0.9)$ & - \\
\hline
\end{tabular}

${ }^{\text {a }}$ Percentage has been calculated as the proportional change in the number of events (spontaneous pregnancy or assisted reproductive technology treatment resulting in pregnancy) for the model population per intervention.

${ }^{\mathrm{b}} \mathrm{IVF}$ : in vitro fertilization.

${ }^{\mathrm{c}}$ ICSI: intracytoplasmic sperm injection.

${ }^{\mathrm{d}}$ IUI: intrauterine insemination.

${ }^{\mathrm{e}}$ Only for the subset of women with BMI over $29 \mathrm{~kg} / \mathrm{m}^{2}$.

${ }^{\mathrm{f}}$ No published data found in literature searches.

Table 3. Effect of each lifestyle intervention on clinical outcomes of pregnancy complications modeled for the Netherlands (modeled per year).

\begin{tabular}{|c|c|c|c|c|}
\hline \multirow[t]{2}{*}{ Intervention } & \multicolumn{4}{|c|}{ Modeled changes in clinical results (per year) } \\
\hline & IUGR $^{\mathrm{a}}, \mathrm{n}(\% \text { change })^{\mathrm{b}}$ & $\begin{array}{l}\text { Gestational diabetes, } \\
\mathrm{n}(\% \text { change })\end{array}$ & $\begin{array}{l}\text { Hypertensive complications, } \\
\mathrm{n}(\% \text { change })\end{array}$ & $\begin{array}{l}\text { Decreased number of premature } \\
\text { births, } \mathrm{n}(\% \text { change })\end{array}$ \\
\hline $\begin{array}{l}\text { Smarter Pregnancy (Slim- } \\
\text { merZwanger) }\end{array}$ & $-1200(-2.6)$ & $-^{c}$ & - & - \\
\hline LIFEstyle & - & $-200(-4.4)$ & $-200(-3.8)$ & $-200(-3.0)$ \\
\hline Smarter Pregnancy + LIFEstyle & $-1200(-2.6)^{\mathrm{d}}$ & $-200(-4.4)^{\mathrm{d}}$ & $-200(-3.8)^{\mathrm{d}}$ & $-200(-3.0)^{\mathrm{d}}$ \\
\hline Smoking cessation (men only) & - & - & - & - \\
\hline Mental health/mindfulness & - & - & - & - \\
\hline
\end{tabular}

${ }^{a}$ IUGR: intrauterine growth restriction.

${ }^{b}$ Percentage has been calculated as the proportional change in the number of events (pregnancy complications) for the model population per intervention).

${ }^{\mathrm{c}}$ No published data found in literature searches.

${ }^{\mathrm{d}}$ Only for the subset of women with BMI over $29 \mathrm{~kg} / \mathrm{m}^{2}$.

\section{Estimated Cost-Savings of Lifestyle Interventions and Sensitivity Analysis}

A summary of the estimated cost savings for each lifestyle intervention is presented in Table 4. The lifestyle intervention that was modeled to have the highest cost saving was LIFEstyle, with an estimated saving of $€ 1163$ (US $\$ 1380.18$ at the time of publication) per couple; however, this intervention is specifically for subfertile obese women. The combination of Smarter Pregnancy and LIFEstyle, for which obese women would have access to both Smarter Pregnancy and LIFEstyle and all other subfertile couples would use Smarter Pregnancy only, was modeled to save $€ 586$ (US $\$ 695.43$ ) per couple. Across the entire potential target group in the Netherlands, the greatest financial saving would be achieved with the combination program Smarter Pregnancy and LIFEstyle ( $€ 27$ million, approximately US \$32 million), followed by Smarter Pregnancy (€24 million, approximately US \$28.4 million) alone. The lifestyle intervention of smoking cessation for men represented the lowest cost saving $€ 41$ (US \$48.66) per couple in the Netherlands. 
Table 4. Estimated cost savings per year of lifestyle interventions (business cases) on assisted reproductive technologies and reduction of pregnancy complications modeled for the Netherlands (an exchange rate of approximately $€ 1=\mathrm{US} \$ 1.19$ is applicable at the time of publication).

\begin{tabular}{|c|c|c|c|c|c|}
\hline Intervention & $\begin{array}{l}\text { Estimated cost bene- } \\
\text { fit per couple }{ }^{\mathrm{a}} \text { (least } \\
\text { favorable, most fa- } \\
\text { vorable scenario) }\end{array}$ & $\begin{array}{l}\text { Total target } \\
\text { group (preva- } \\
\text { lence) }\end{array}$ & $\begin{array}{l}\text { Total annual } \\
\text { target group } \\
\text { (incidence) }\end{array}$ & $\begin{array}{l}\text { Estimated overall cost saving } \\
\text { (least favorable, most favorable } \\
\text { scenario) per year }^{\mathrm{a}}\end{array}$ & $\begin{array}{l}\text { Estimated total assisted reproduc- } \\
\text { tive technology cost saving per } \\
\text { year (least favorable, most favor- } \\
\text { able scenario) }^{b}\end{array}$ \\
\hline $\begin{array}{l}\text { Smarter Pregnancy } \\
\text { (SlimmerZwanger) }\end{array}$ & $€ 513(€ 100, € 2200)$ & 46,000 & 1191 & $€ 24 \mathrm{M}(€ 4.6 \mathrm{M}, € 101.2 \mathrm{M})$ & $€ 6 \mathrm{M}(€ 1.2 \mathrm{M}, € 26.2 \mathrm{M})$ \\
\hline LIFEstyle & $€ 1163(€ 900, € 1600)$ & 5400 & 1391 & $€ 6 \mathrm{M}(€ 4.9 \mathrm{M}, € 8.6 \mathrm{M})$ & $€ 1.6 \mathrm{M}(€ 1.3 \mathrm{M}, € 101 \mathrm{M})$ \\
\hline $\begin{array}{l}\text { Smarter Pregnancy + } \\
\text { LIFEstyle }\end{array}$ & $€ 586(€ 100, € 2200)$ & 46,000 & 1191 & $€ 27 \mathrm{M}(€ 4.6 \mathrm{M}, € 101 \mathrm{M})$ & $€ 7 \mathrm{M}(€ 4.6 \mathrm{M}, € 26.4 \mathrm{M})$ \\
\hline $\begin{array}{l}\text { Smoking cessation } \\
\text { (men only) }\end{array}$ & $€ 41(€-20, € 170)$ & 3200 & 826 & $€ 0.130 \mathrm{M}(€-0.064 \mathrm{M}, € 0.54 \mathrm{M})$ & $€ 0.034 \mathrm{M}(€-0.017 \mathrm{M}, € 0.140 \mathrm{M})$ \\
\hline $\begin{array}{l}\text { Mental health/ Mind- } \\
\text { fulness }\end{array}$ & $€ 36(€-190, € 500)$ & 13,700 & 3551 & $€ 4.9 \mathrm{M}(€-2.6 \mathrm{M}, € 6.9 \mathrm{M})$ & $€ 1.3 \mathrm{M}(€-0.7 \mathrm{M}, € 1.8 \mathrm{M})$ \\
\hline
\end{tabular}

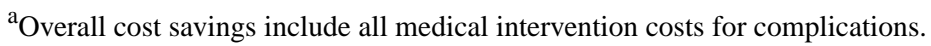

${ }^{\mathrm{b}}$ Includes cost savings for assisted reproductive technology procedures that would no longer be necessary.

\section{Discussion}

\section{Principal Results}

Using a model population based on subfertile couples and subfertile obese women living in the Netherlands undergoing IVF, ICSI, or IUI, we developed a hypothesis-based model using quantitative parameters from published literature and expert opinion to explore how 5 selected lifestyle intervention programs, each using different approaches and targets, can potentially improve the chances of spontaneous pregnancy, reduce the number of cycles of IVF, ICSI, or IUI treatments, and reduce the chance of adverse maternal pregnancy and birth outcomes. As part of the analysis our model also assessed potential cost savings of the selected lifestyle intervention programs for the model population. In order to estimate the cost savings, we calculated the estimated cost savings per couple for each of the selected lifestyle intervention programs. Multiplying this number with the size of the target group of the selected lifestyle intervention program yielded the total estimated cost savings. Cost savings per couple were modeled for each of the lifestyle programs taking into account the cost savings achieved by reducing the volume of fertility care, as well as cost savings achieved due to a reduction of pregnancy complications. Estimated costs of the lifestyle intervention were subsequently subtracted from these savings, in order to achieve the total cost savings of the lifestyle intervention. For each lifestyle intervention, the model only included the fertility treatments and complications that the lifestyle intervention was known to have an effect upon using available evidence.

Modifiable lifestyle factors were selected based on their positive associations with the likelihood of spontaneous conception or successful fertility treatment and thus would be most relevant for evaluating in terms of potential cost saving. Age was considered to be important but not modifiable at the moment of the health care visit. In men, moderate alcohol consumption, caffeine intake, and scrotal temperature were considered less relevant lifestyle factors and, therefore, were not included in our model. Thus, the most important modifiable factors were maternal BMI (used as a surrogate marker of health and lifestyle), diet, physical activity, smoking, and stress. These factors had sufficient published quantitative data regarding their impact on reproductive health, fertility treatment, and pregnancy complications to develop our model and have also used by others $[9,11,12,16,20,24]$.

In our model, both Smarter Pregnancy and LIFEstyle increased the number of spontaneous pregnancies by $13.0 \%$ and $9.9 \%$ per couple, respectively, compared with no lifestyle intervention. This supports data from another study that showed that a 1-point increase in a pre-conception dietary risk score was associated with $65 \%$ increased chance of ongoing pregnancy [27] and a "Mediterranean"-style diet is likely to improve IVF and ICSI treatment success with an increased probability of pregnancy (odds ratio 1.4, 95\% CI 1.0-1.9) [28]. Similarly, in our model, these 2 lifestyle interventions decreased the number of IVF, ICSI, and IUI cycles required for a successful pregnancy. Although there were no data available for the effect of smoking cessation in men and mindfulness mental health support on spontaneous pregnancies or number of IUI treatments, our model suggests that both may decrease the number of IVF and ICSI treatments required for a successful pregnancy.

Our model also showed that validated lifestyle interventions may contribute to a reduction of pregnancy complications, including fetal growth restriction, gestational diabetes, hypertensive complications and premature births. Published clinical data about fetal growth restriction were only available to model Smarter Pregnancy, for which there was a $2.6 \%$ decreased occurrence of fetal growth restriction per couple. Indeed, the evidence for pre-conception nutrition associated with birth weight is compelling, with studies advocating "Mediterranean"-style diets high in fruit, vegetables, vegetable oil, fish, pasta, and rice as well as lower consumption of meat and potatoes $[28,29]$. For example, the size of the embryo represented by the crown-rump length is improved by an energy-rich nutritious diet (effect estimate 1.62, 95\% CI $0.52-2.72 ; P<.05)$ [29]. Moreover, pre-conception diets with increased pre-conception omega-3 polyunsaturated fatty acid intake from fruit and vegetables was associated with improved 
embryo morphology (linear regression coefficient $\beta=0.6, P \leq .05$ ) [30]. Similarly, a "traditional Western" diet (high intake potatoes, mayonnaise and other fatty sauces, meat products, refined grains, sugar, and confectionary) was associated with an sperm DNA damage (linear regression coefficient $\beta=13.25$, $P=.01$ ), whereas a "health conscious" diet (high intakes of fruit, vegetables, fish and other seafood, whole grains and legumes) was inversely associated with sperm DNA damage $(\beta=-2.81$, $P=.05)[31]$.

In contrast, published clinical data on gestational diabetes, hypertensive complications, and premature births were only available to model LIFEstyle, the pre-conception intervention to help obese women lose weight prior to and during early pregnancy. We modeled that implementation of the LIFEstyle program for obese women in the Netherlands seeking reproductive assistance may result in $4.4 \%$ lower chance of gestational diabetes, $3.8 \%$ lower chance of hypertensive complications, and $3.0 \%$ chance of premature birth. In subanalyses of the LIFEstyle study, women in the intervention group significantly reduced their consumption of sugary drinks and savory snacks, as well as increased their physical activity [32], and reduced the likelihood of developing metabolic syndrome [33]. A recent meta-analysis has shown that healthy diets (Mediterranean Diet, Dietary Approaches to Stop Hypertension diet and Alternate Healthy Eating Index diet) were associated with $15 \%-38 \%$ reduced relative risk of gestational diabetes, and compared with no physical activity, any prepregnancy or early pregnancy physical activity was associated with $30 \%$ and $21 \%$ reduced odds of gestational diabetes, respectively [34].

Our model also showed that lifestyle intervention programs are cost-effective to improve the chances of pregnancy [2]. It should be noted, however, that our estimated cost savings are conservative, as we did not include the cost of ovulation induction in our model. Moreover, we used conservative data regarding the number of subfertile men and women in the Netherlands. In our model, LIFEstyle has the greatest cost saving of $€ 1163$ (US \$1380.18) per couple, which was similar to a cost analysis of the LIFEstyle study showed an overall saving of $€ 1278$ (US \$1512.92) per couple [17].

\section{Limitations}

Inherent to the model-based approach using existing literature and expert opinion input data, we show results which may not completely reflect the real-world. Moreover, we did not model the costs for ovulation induction as it has a high success rate for anovulatory infertility. Although our model was based on couples living in the Netherlands, it nevertheless reflects couples seeking fertility assistance in other wealthy developed countries, such as those in Western Europe, North America, and Australia [35]. Published literature pertaining some pregnancy outcomes was not available, which necessitated assumptions being made. The costs of fertility treatment vary greatly depending on country and assisted reproductive technology procedures used, and the costs of some procedures are uncertain. We modeled the potential impact on reproductive and cost of fertility treatment rather than collecting real-world data. Although every effort was made to include evidence-based input parameters, the prevalence of subfertility among men and women living in the Netherlands may have been underestimated in our model. However, by using a conservative estimate of the number, the results of our model are also conservative, meaning that it is possible that there could be greater overall reductions in the number of IVF, ICSI, and IUI treatments required, fewer pregnancy complications, and larger cost savings than we have reported here. It is important to stress that the estimated cost savings are likely an underestimation, as we have not modeled more indirect cost savings that likely are achieved by reducing pregnancy complications, such as for instance, a more expedited return to the workforce for the mother, as well as improved health of the newborn which likely will lead to fewer health care expenditures in the years following birth. In addition, we have not included cost savings that can reasonably be expected as a result of improved lifestyle in the mother and father, likely leading to fewer health care expenditures as well as potentially a greater contribution to the workforce (and therefore taxation).

In our model, we included a comparison of the effects of smoking on IVF and ICSI outcomes in men. To date, there have been no published studies on pregnancy outcomes regarding the use of smoking cessation apps or programs in couples seeking to become pregnant, therefore, we have likely underestimated the effects of smoking cessation on pregnancy outcomes and the cost implications of smoking cessation in terms of reducing the need for fertility assistance and pregnancy complications. In addition, the effects of second-hand smoke have not been considered in our model.

Another limitation is that the costs of fertility treatment vary greatly depending on country and procedures required, and the costs of some procedures are uncertain. The type of fertility treatment required would depend on the cause of subfertility, which we have not included or addressed in our model. Further investigations are required to understand to what extent lifestyle modifications can reduce the risk of pregnancy complications, as well as affect direct outcomes of fertility treatment.

\section{Comparisons With Prior Work}

Our model input parameters were mostly based on good-quality evidence from published literature; however, as is inherently the case with hypothesis-based modeling, some assumptions were made. There have been 2 randomized controlled trials $[9,10]$ that have investigated pre-conception lifestyle interventions to help obese women to lose weight. Although the study LIFEstyle [11] did not increase the healthy live birth rate, there was an increased rate of spontaneous pregnancies specifically among anovulatory women. A further exploratory analysis [13] suggested that a periconceptional decrease in BMI in obese subfertile women could lead to a decrease of the rates of hypertensive pregnancy complications and preterm birth; however, further randomized controlled trials are required to confirm these results. Similarly, in the second study, significantly more live births were achieved through spontaneous pregnancies in the weight reduction group $(10.5 \%)$ than in the control group $(2.6 \% ; P=.009)$ [10]. Results from another randomized controlled trial, the UK Pregnancies Better Eating and Activity Trial (UPBEAT) [36], showed that specific dietary patterns in obese women in early pregnancy are linked to 
gestational diabetes; however, the early pregnancy UPBEAT intervention did not reduce the incidence of gestational diabetes in its cohort [37]. Nevertheless, a secondary analysis of UPBEAT suggested that women randomized to the UPBEAT intervention had healthier metabolic profiles than those who received standard care [38]. As such, overweight or obese couples are likely to benefit from pre-conception lifestyle modifications of improved nutrition and physical activity prior to fertility treatment in an effort increase the chances of spontaneous conception and to help reduce pregnancy complications of gestational diabetes, hypertensive complications, and preterm birth. Improving lifestyle during the periconception period (defined as at least 14 weeks before conception) and the first 10 weeks of pregnancy is likely to help alleviate the risk of several adverse birth outcomes, such as congenital malformations, fetal growth restriction and babies born small or large for gestational age, as well as maternal pregnancy complications such as gestational diabetes, hypertensive disorders, and premature delivery [11-13,27].

Our data are also supported by a previous model-based cost analysis for Smarter Pregnancy used by 793 subfertile women undergoing IVF treatment [2]. This program resulted in 86 additional pregnancies and saved $€ 270,000$ (approximately US $\$ 319,630$ ) compared to usual care after 2 IVF cycles, with an incremental cost-effectiveness ratio of $€-3050$ (95\% CI $€-3960$ to $€-540$; or approximately US $\$-3611,95 \%$ CI US \$-4688 to US \$-639) per additional pregnancy. The largest cost saving was from avoided IVF treatment costs. Sensitivity analyses showed that Smarter Pregnancy would need to increase the ongoing pregnancy rate by at least $51 \%$ after 2 IVF cycles for cost saving. Thus, Smarter Pregnancy is potentially cost saving for subfertile couples after their first IVF treatment.

There have been no published randomized controlled trials specifically on pre-conception interventions to quit smoking or to reduce or stop alcohol consumption. Nevertheless, Smarter Pregnancy has assessed pre-conception healthy nutrition and lifestyle, including tailored advice based on questionnaire responses regarding smoking and alcohol consumption in both couples seeking fertility treatment, and couples conceiving spontaneously [12]. Importantly, the Smarter Pregnancy intervention has been the only study to show a positive correlation between women whose partners also made positive lifestyle modifications and achieving pregnancy [20]. In addition, Smarter Pregnancy was not tailored for obese women and their partner, but these couples also appreciated the program very much and showed comparable effectiveness. There remains a lack of randomized controlled trials in this area as first highlighted by a Cochrane review nearly a decade ago [39].

Current evidence on the effectiveness of internet or app-based interventions is limited, and further investigation is needed in order to fully appraise their impact on fertility outcomes such as pregnancy rate, as well as pregnancy complications and newborn health. A recent systematic review [40] looked into feasibility, acceptability, and effectiveness of mobile health lifestyle and medical apps during pregnancy in high-income countries, which may be an appropriate way of offering lifestyle intervention support to subfertile couples in the future. Lifestyle apps that aimed to improve health behavior, reduce gestational weight gain, and for smoking cessation were generally effective [40]. As such, internet-based technologies such as Smarter Pregnancy have the potential to answer some of these questions as well as raise awareness around the importance of pre-conception care when trying to conceive [21]. Moreover, cognitive behavior therapy or psychological support during fertility treatment is suggested to lead to significantly more viable pregnancies than routine care [41]. As such, pre-conception lifestyle interventions, including medical apps, have the potential to increase ongoing pregnancy rates and birth outcomes in subfertile couples [40].

We do not yet know if various lifestyle modifications such as smoking, alcohol, and nutrition have different effects that depend on the socioeconomic status, educational level, or social background of the couple trying to conceive. Recent analysis of Smarter Pregnancy suggests that the program has been more effective in women living in nondeprived neighborhoods, who were, however, less likely to complete the 24 weeks of coaching than women who lived in deprived neighborhoods [42]. Although subfertile couples seeking fertility treatment are often intrinsically motivated to make positive lifestyle changes to improve the likelihood of a successful pregnancy, the socioeconomic status of couples may impact lifestyle as well as their ability to change lifestyle habits.

\section{Conclusions}

In summary, lifestyle is an important public health issue that has a significant and cumulative impact on fertility. Appropriate counseling could result in substantial reductions in the referrals for fertility investigations and treatments [27]. In order to maximize the pregnancy rates during fertility care, many subfertile couples could benefit from pre-conception lifestyle interventions delivered before fertility treatment. Although more research is needed regarding the use of internet- and app-based technologies for lifestyle and lifestyle interventions prior to fertility treatment, our results can be used to support subfertile couples, fertility care providers, and policy makers involved in public health to optimize clinical outcomes at affordable costs. Pre-conception lifestyle interventions are likely to be a cost-effective way of supporting subfertile couples trying to conceive. Further implementation of the app Smarter Pregnancy also designed for subfertile couples seeking fertility assistance is likely to be cost-effective and allow data on reproductive outcomes to be collected.

\section{Acknowledgments}

Christina Birch Olsen, an employee of Ferring International, conducted literature searches. Celia J Parkyn, PhD, provided medical writing and linguistic support during manuscript development, and was funded by Ferring BV. The fertility expert working group advisory board meetings, the cost-effectiveness modeling of the lifestyle interventions and medical writing support was funded by Ferring BV. 


\section{Authors' Contributions}

RS-T, JL, EC, and LS made substantial contributions to the conception and design of the study. EC, LS, and LV made substantial contributions to the literature search, the acquisition of data, and data analysis. RS-T, AH, HG, and JL provided additional data needed for the model. All authors also attended 3 advisory workshops to discuss fertility and lifestyle interventions. LS and LV developed the fertility outcomes and cost-effectiveness model. All authors made substantial contributions to the interpretation of data. All authors critically reviewed multiple versions of the manuscript during development, including a draft outline as well as full drafts. All authors approved the final version of the manuscript.

\section{Conflicts of Interest}

EC is employed by Ferring BV, which funded this research. LS is and LV was (during data collection, analysis, and manuscript preparation) employed by KPMG and are advisors to Ferring BV. AH, HG, AB, GD, MS, JS, and JL received payment from Ferring BV, for attending the fertility expert working group advisory board meetings. The department of Obstetrics and Gynecology at the University Medical Center Groningen Hanzeplein received an unrestricted educational grant from Ferring BV. RS-T contributed from the department of Obstetrics and Gynecology, Erasmus University Medical Center, and as consultant of eHealth Care Solutions, to one working group meeting for which she received one payment from Ferring BV. JL received unrestricted research grants from Ferring BV, ZonMw, and the Dutch Heart Association. He also received consultancy fees from the following companies: Danone, Euroscreen/Ogeda, Ferring BV, and Titus Healthcare.

\section{Multimedia Appendix 1}

Table S1: Input parameters for specific lifestyle interventions per year.

[DOCX File, 43 KB-Multimedia Appendix 1]

\section{Multimedia Appendix 2}

Table S2: Input parameters - assisted reproductive technology costs, assumptions and fertility data from the Netherlands. [DOCX File, 24 KB-Multimedia Appendix 2]

\section{References}

1. Gormack AA, Peek JC, Derraik JGB, Gluckman PD, Young NL, Cutfield WS. Many women undergoing fertility treatment make poor lifestyle choices that may affect treatment outcome. Hum Reprod 2015 Jul;30(7):1617-1624. [doi: 10.1093/humrep/dev094] [Medline: 25924654]

2. Oostingh EC, Hall J, Koster MPH, Grace B, Jauniaux E, Steegers-Theunissen RPM. The impact of maternal lifestyle factors on periconception outcomes: a systematic review of observational studies. Reprod Biomed Online 2019 Jan;38(1):77-94. [doi: 10.1016/j.rbmo.2018.09.015] [Medline: 30424937]

3. Rossi BV, Abusief M, Missmer SA. Modifiable risk factors and infertility: what are the connections? Am J Lifestyle Med 2014;10(4):220-231 [FREE Full text] [doi: 10.1177/1559827614558020] [Medline: 27594813]

4. Heindel JJ, Vandenberg LN. Developmental origins of health and disease: a paradigm for understanding disease cause and prevention. Curr Opin Pediatr 2015 Apr;27(2):248-253 [FREE Full text] [doi: 10.1097/MOP.0000000000000191] [Medline: 25635586]

5. Hanson M, Gluckman P, Bustreo F. Obesity and the health of future generations. Lancet Diabetes Endocrinol 2016 Dec;4(12):966-967. [doi: 10.1016/S2213-8587(16)30098-5] [Medline: 27743979]

6. Sermondade N, Faure C, Fezeu L, Shayeb AG, Bonde JP, Jensen TK, et al. BMI in relation to sperm count: an updated systematic review and collaborative meta-analysis. Hum Reprod Update 2013;19(3):221-231 [FREE Full text] [doi: 10.1093/humupd/dms050] [Medline: 23242914]

7. Norman RJ, Mol BWJ. Successful weight loss interventions before in vitro fertilization: fat chance? Fertil Steril 2018 Sep;110(4):581-586. [doi: 10.1016/j.fertnstert.2018.05.029] [Medline: 30196941]

8. Best D, Avenell A, Bhattacharya S, Stadler G. New debate: is it time for infertility weight-loss programmes to be couple-based? Hum Reprod 2017 Dec 01;32(12):2359-2365. [doi: 10.1093/humrep/dex313] [Medline: 29040540]

9. Mutsaerts MAQ, van Oers AM, Groen H, Burggraaff JM, Kuchenbecker WKH, Perquin DAM, et al. Randomized trial of a lifestyle program in obese infertile women. N Engl J Med 2016 May 19;374(20):1942-1953. [doi: 10.1056/NEJMoa1505297] [Medline: 27192672]

10. Einarsson S, Bergh C, Friberg B, Pinborg A, Klajnbard A, Karlström P, et al. Weight reduction intervention for obese infertile women prior to IVF: a randomized controlled trial. Hum Reprod 2017 Aug 01;32(8):1621-1630. [doi: 10.1093/humrep/dex235] [Medline: 28854592]

11. van Oers AM, Groen H, Mutsaerts MAQ, Burggraaff JM, Kuchenbecker WKH, Perquin DAM, LIFEstyle study group. Effectiveness of lifestyle intervention in subgroups of obese infertile women: a subgroup analysis of a RCT. Hum Reprod 2016 Dec;31(12):2704-2713. [doi: 10.1093/humrep/dew252] [Medline: 27798042] 
12. van Dijk MR, Koster MPH, Willemsen SP, Huijgen NA, Laven JSE, Steegers-Theunissen RPM. Healthy preconception nutrition and lifestyle using personalized mobile health coaching is associated with enhanced pregnancy chance. Reprod Biomed Online 2017 Oct;35(4):453-460. [doi: 10.1016/j.rbmo.2017.06.014] [Medline: 28688924]

13. van Oers AM, Mutsaerts MAQ, Burggraaff JM, Kuchenbecker WKH, Perquin DAM, Koks CAM, LIFEstyle study group. Association between periconceptional weight loss and maternal and neonatal outcomes in obese infertile women. PLoS One 2018;13(3):e0192670 [FREE Full text] [doi: 10.1371/journal.pone.0192670] [Medline: 29590118]

14. de Klerk C, Hunfeld JAM, Duivenvoorden HJ, den Outer MA, Fauser BCJM, Passchier J, et al. Effectiveness of a psychosocial counselling intervention for first-time IVF couples: a randomized controlled trial. Hum Reprod 2005 May;20(5):1333-1338. [doi: 10.1093/humrep/deh748] [Medline: 15650042]

15. Gameiro S, Boivin J, Dancet E, de Klerk C, Emery M, Lewis-Jones C, et al. ESHRE guideline: routine psychosocial care in infertility and medically assisted reproduction-a guide for fertility staff. Hum Reprod 2015 Nov;30(11):2476-2485. [doi: 10.1093/humrep/dev177] [Medline: 26345684]

16. Li J, Long L, Liu Y, He W, Li M. Effects of a mindfulness-based intervention on fertility quality of life and pregnancy rates among women subjected to first in vitro fertilization treatment. Behav Res Ther 2016 Feb;77:96-104. [doi: 10.1016/j.brat.2015.12.010] [Medline: 26742022]

17. van Oers AM, Mutsaerts MAQ, Burggraaff JM, Kuchenbecker WKH, Perquin DAM, Koks CAM, LIFEstyle study group. Cost-effectiveness analysis of lifestyle intervention in obese infertile women. Hum Reprod 2017 Dec 01;32(7):1418-1426. [doi: 10.1093/humrep/dex092] [Medline: 28486704]

18. Gordon JS, Armin J, Giacobbi P, Cunningham JK, Johnson T, Abbate K, et al. Development and evaluation of the See Me Smoke-Free multi-behavioral mHealth app for women smokers. Transl Behav Med 2017 Feb 02. [doi: 10.1007/s13142-017-0463-7] [Medline: 28155107]

19. Schmidt CA, Romine JK, Bell ML, Armin J, Gordon JS. User Participation and Engagement With the See Me Smoke-Free mHealth App: Prospective Feasibility Trial. JMIR Mhealth Uhealth 2017 Oct 09;5(10):e142 [FREE Full text] [doi: 10.2196/mhealth.7900] [Medline: 28993302]

20. van Dijk MR, Huijgen NA, Willemsen SP, Laven JS, Steegers EA, Steegers-Theunissen RP. Impact of an mHealth Platform for Pregnancy on Nutrition and Lifestyle of the Reproductive Population: A Survey. JMIR Mhealth Uhealth 2016 May 27;4(2):e53 [FREE Full text] [doi: 10.2196/mhealth.5197] [Medline: 27234926]

21. van Dijk MR, Koster MP, Rosman AN, Steegers-Theunissen RP. Opportunities of mHealth in Preconception Care: Preferences and Experiences of Patients and Health Care Providers and Other Involved Professionals. JMIR Mhealth Uhealth 2017 Aug 17;5(8):e123 [FREE Full text] [doi: 10.2196/mhealth.7834] [Medline: 28818820]

22. Hajizadeh Maleki B, Tartibian B, Chehrazi M. The effects of three different exercise modalities on markers of male reproduction in healthy subjects: a randomized controlled trial. Reproduction 2017 Feb;153(2):157-174. [doi: 10.1530/REP-16-0318] [Medline: 27920258]

23. Hajizadeh Maleki B, Tartibian B. Moderate aerobic exercise training for improving reproductive function in infertile patients: A randomized controlled trial. Cytokine 2017 Apr;92:55-67. [doi: 10.1016/j.cyto.2017.01.007] [Medline: 28092795]

24. Zitzmann M, Rolf C, Nordhoff V, Schräder G, Rickert-Föhring M, Gassner P, et al. Male smokers have a decreased success rate for in vitro fertilization and intracytoplasmic sperm injection. Fertil Steril 2003 Jun;79 Suppl 3:1550-1554. [doi: 10.1016/s0015-0282(03)00339-x] [Medline: 12801558]

25. Open data from the Dutch Health Authority. Nederlandse Zorgautoriteit. URL: http://www.opendisdata.nl [accessed 2018-08-13]

26. Dutch Agency for Statistics. StatLine (CBS). URL: https://opendata.cbs.nl/ [accessed 2019-11-09]

27. Twigt JM, Bolhuis MEC, Steegers EAP, Hammiche F, van IWG, Laven JSE, et al. The preconception diet is associated with the chance of ongoing pregnancy in women undergoing IVF/ICSI treatment. Hum Reprod 2012 Aug;27(8):2526-2531. [doi: 10.1093/humrep/des157] [Medline: 22593431]

28. Vujkovic M, de Vries JH, Lindemans J, Macklon NS, van der Spek PJ, Steegers EAP, et al. The preconception Mediterranean dietary pattern in couples undergoing in vitro fertilization/intracytoplasmic sperm injection treatment increases the chance of pregnancy. Fertil Steril 2010 Nov;94(6):2096-2101. [doi: 10.1016/j.fertnstert.2009.12.079] [Medline: 20189169]

29. Bouwland-Both MI, Steegers-Theunissen RPM, Vujkovic M, Lesaffre EMEH, Mook-Kanamori DO, Hofman A, et al. A periconceptional energy-rich dietary pattern is associated with early fetal growth: the Generation R study. BJOG 2013 Mar;120(4):435-445 [FREE Full text] [doi: 10.1111/1471-0528.12086] [Medline: 23194298]

30. Hammiche F, Vujkovic M, Wijburg W, de Vries JHM, Macklon NS, Laven JSE, et al. Increased preconception omega-3 polyunsaturated fatty acid intake improves embryo morphology. Fertil Steril 2011 Apr;95(5):1820-1823. [doi: 10.1016/j.fertnstert.2010.11.021] [Medline: 21130435]

31. Vujkovic M, de VJH, Dohle GR, Bonsel GJ, Lindemans J, Macklon NS, et al. Associations between dietary patterns and semen quality in men undergoing IVF/ICSI treatment. Hum Reprod 2009 Jun;24(6):1304-1312. [doi: 10.1093/humrep/dep024] [Medline: 19228759]

32. van Elten TM, Karsten MDA, Geelen A, van Oers AM, van Poppel MNM, Groen H, LIFEstyle study group. Effects of a preconception lifestyle intervention in obese infertile women on diet and physical activity; A secondary analysis of a 
randomized controlled trial. PLoS One 2018;13(11):e0206888 [FREE Full text] [doi: 10.1371/journal.pone.0206888] [Medline: $\underline{30403756]}$

33. van Dammen L, Wekker V, van Oers AM, Mutsaerts MAQ, Painter RC, Zwinderman AH, LIFEstyle study group. Effect of a lifestyle intervention in obese infertile women on cardiometabolic health and quality of life: A randomized controlled trial. PLoS One 2018;13(1):e0190662 [FREE Full text] [doi: 10.1371/journal.pone.0190662] [Medline: 29324776]

34. Mijatovic-Vukas J, Capling L, Cheng S, Stamatakis E, Louie J, Cheung NW, et al. Associations of Diet and Physical Activity with Risk for Gestational Diabetes Mellitus: A Systematic Review and Meta-Analysis. Nutrients 2018 May 30;10(6) [FREE Full text] [doi: 10.3390/nu10060698] [Medline: 29849003]

35. Noncommunicable Diseases Country Profiles, 2018. World Health Organization. URL: $\underline{\text { http://www.who.int/nmh/publications/ }}$ ncd-profiles-2018/en/

36. Flynn AC, Seed PT, Patel N, Barr S, Bell R, Briley AL, UPBEAT consortium. Dietary patterns in obese pregnant women; influence of a behavioral intervention of diet and physical activity in the UPBEAT randomized controlled trial. Int J Behav Nutr Phys Act 2016 Nov 29;13(1):124 [FREE Full text] [doi: 10.1186/s12966-016-0450-2] [Medline: 27894316]

37. Poston L, Bell R, Croker H, Flynn AC, Godfrey KM, Goff L, UPBEAT Trial Consortium. Effect of a behavioural intervention in obese pregnant women (the UPBEAT study): a multicentre, randomised controlled trial. Lancet Diabetes Endocrinol 2015 Oct;3(10):767-777 [FREE Full text] [doi: 10.1016/S2213-8587(15)00227-2] [Medline: 26165396]

38. Mills HL, Patel N, White SL, Pasupathy D, Briley AL, Santos Ferreira DL, UPBEAT Consortium. The effect of a lifestyle intervention in obese pregnant women on gestational metabolic profiles: findings from the UK Pregnancies Better Eating and Activity Trial (UPBEAT) randomised controlled trial. BMC Med 2019 Jan 21;17(1):15 [FREE Full text] [doi: 10.1186/s12916-018-1248-7] [Medline: 30661507 ]

39. Anderson K, Norman RJ, Middleton P. Preconception lifestyle advice for people with subfertility. Cochrane Database Syst Rev 2010 Apr 14(4):CD008189. [doi: 10.1002/14651858.CD008189.pub2] [Medline: 20393968]

40. Overdijkink SB, Velu AV, Rosman AN, van BMD, Kok M, Steegers-Theunissen RP. The usability and effectiveness of mobile health technology-based lifestyle and medical intervention apps supporting health care during pregnancy: systematic review. JMIR Mhealth Uhealth 2018 Apr 24;6(4):e109 [FREE Full text] [doi: 10.2196/mhealth.8834] [Medline: 29691216]

41. Domar AD, Clapp D, Slawsby EA, Dusek J, Kessel B, Freizinger M. Impact of group psychological interventions on pregnancy rates in infertile women. Fertil Steril 2000 Apr;73(4):805-811. [doi: 10.1016/s0015-0282(99)00493-8] [Medline: 10731544]

42. Gootjes DV, van Dijk MR, Koster MP, Willemsen SP, Steegers EA, Steegers-Theunissen RP. Neighborhood Deprivation and the Effectiveness of Mobile Health Coaching to Improve Periconceptional Nutrition and Lifestyle in Women: Survey in a Large Urban Municipality in the Netherlands. JMIR Mhealth Uhealth 2019 Apr 11;7(4):e11664 [FREE Full text] [doi: 10.2196/11664] [Medline: $\underline{30973345]}$
Abbreviations
BMI: body mass index
IUI: intrauterine insemination
IVF: in vitro fertilization
ICSI: intracytoplasmic sperm injection
UPBEAT: UK Pregnancies Better Eating And Activity Trial

Edited by G Eysenbach; submitted 23.04.20; peer-reviewed by A Rosman, R Poluru; comments to author 12.06.20; revised version
received 25.07.20; accepted 16.08.20; published 23.11.20
Please cite as:
Steegers-Theunissen R, Hoek A, Groen H, Bos A, van den Dool G, Schoonenberg M, Smeenk J, Creutzberg E, Vecht L, Starmans L,
Laven J
Pre-Conception Interventions for Subfertile Couples Undergoing Assisted Reproductive Technology Treatment: Modeling Analysis
JMIR Mhealth Uhealth 2020;8(11):e19570
URL: https:///mhealth.jmir.org/2020/11/e19570
doi: $10.2196 / 19570$
PMID: $\underline{3226349}$

CRégine Steegers-Theunissen, Annemieke Hoek, Henk Groen, Annelies Bos, Grada van den Dool, Marieke Schoonenberg, Jesper Smeenk, Eva Creutzberg, Loes Vecht, Luc Starmans, Joop Laven. Originally published in JMIR mHealth and uHealth (http://mhealth.jmir.org), 23.11.2020. This is an open-access article distributed under the terms of the Creative Commons Attribution License (https://creativecommons.org/licenses/by/4.0/), which permits unrestricted use, distribution, and reproduction in any 
medium, provided the original work, first published in JMIR mHealth and uHealth, is properly cited. The complete bibliographic information, a link to the original publication on http://mhealth.jmir.org/, as well as this copyright and license information must be included. 